\title{
CONSTRUINDO A DISCIPLINA DE PSICOFARMACOLOGIA E APRENDIZAGEM COM ALUNOS DE UM CURSO DE PÓS-GRADUAÇÃO A PARTIR DE CÍRCULOS DE DIÁLOGO E COMPREENSÃO
}

\author{
Daniela Copetti Santos ${ }^{1}$
}

\begin{abstract}
RESUMO
Este artigo tem como propósito refletir sobre as dificuldades enfrentadas pelos alunos na aprendizagem e os fatores relacionados ao uso demasiado de medicamentos, principalmente em idade escolar. Essas reflexões serão feitas a partir da construção de círculos de diálogo e compreensão, quando cada pós-graduando terá a oportunidade de trazer as suas experiências vividas em sala de aula com os seus alunos. Os círculos de diálogo são baseados na Escuta - e dentro desta a Presença, a Atenção e o Silêncio de cada participante. Fazendo uso dessa metodologia, foi possível estruturar a disciplina de Psicofarmacologia e Aprendizagem ministrada no curso de Pós-Graduação em Neuropsicopedagogia Clínica e Institucional. Por meio dessa construção entre professor e alunos foi possível explorar diferentes áreas, entre elas Farmacologia, Neurociência, Pedagogia Social e Psicologia. Verificamos que o uso de medicamentos em indivíduos, principalmente na infância e adolescência, ocorre de forma errada, com grandes quantidades, altas dosagens e, muitas vezes, sem um diagnóstico correto. Diagnósticos eficazes são necessários, além de conhecer o aluno e seu histórico de vida, considerando que boas doses de amor, carinho e atenção são fundamentais durante o seu desenvolvimento escolar.
\end{abstract}

Palavras-chave: Alunos. Aprendizagem. Psicofarmacologia.

\section{BUILDING THE DISCIPLINE OF PSYCHOPHARMACOLOGY AND LEARNING WITH STUDENTS} OF A POSTGRADUATE COURSE FROM CIRCLES OF DIALOGUE AND COMPREHENSION

\begin{abstract}
This article aims to reflect on the difficulties faced by students in learning and the factors related to the use of medications, especially in school age. These reflections will be made from the construction of dialogue circles and understanding where each graduate will have the opportunity to bring their experiences in the classroom with their students. The dialogue circles are based on the listening - and within this the presence, attention and silence of each participant. Using this methodology, it was possible to structure the discipline of psychopharmacology and learning taught in the postgraduate course in clinical and institutional neuropsychopedagogy. Through this construction between teachers and students it was possible to explore different areas, including: Pharmacology, neuroscience, Social pedagogy and psychology. We verified that often the use of medications in individuals, especially in childhood and adolescence, occurs wrongly, large quantities, high dosages and often without a correct diagnosis. It is necessary to know the student, his life history, considering that good doses of love, affection and attention are fundamental during his school development.
\end{abstract}

Keywords: Students. Learning. Psychopharmacology.

RECEBIDO EM: 17/6/2019

ACEITO EM: $16 / 4 / 2020$

\footnotetext{
1 Instituto Federal de Educação, Ciência e Tecnologia Farroupilha - Campus Santa Rosa. Av. Cel. Bráulio de Oliveira, 1400 - Bairro Central. CEP: 98787-740. Santa Rosa/RS, Brasil. http://lattes.cnpq.br/3000585794868964. https://orcid.org/0000-0001-6032-5729. daniela.copetti@iffarroupilha.edu.br
} 
A aprendizagem é deliberada como um processo de modificações do indivíduo, sendo evolutiva e constante. Trata-se da capacidade em adquirir, construir e adaptar o conhecimento e as habilidades, que podem ser realizadas de diversas formas. Por sua vez, a dificuldade de aprendizagem caracteriza-se pelos obstáculos em apreender e construir mais elevado que o naturalmente esperado para uma pessoa considerada normal (dentro da expectativa), confrontando-se educandos de mesma faixa etária. "Suas causas podem ser de natureza psicológica, emocional, neurológica e até mesmo hereditária" (GONÇALVES; OVÍDIO, 2017). Weiss e Cruz (2011) afirmam que crianças com dificuldades de aprendizagem não apresentam distúrbios neurobiológicos; isto quer dizer que os problemas apresentados têm caráter provisório e, além das causas citadas pelo autor anteriormente, elas ocupam outras dimensões no indivíduo, como social, pedagógica, psicoafetiva, psicocognitiva e orgânica. A dimensão social perpassa todas as demais, que, por sua vez, apresentam pontos de intersecção. Sendo assim, a dificuldade de aprendizagem deve ser vista sempre na perspectiva da pluricausalidade (WEISS, 2009).

Embasado nesse discurso, surge a disciplina de Psicofarmacologia e Aprendizagem ministrada no curso de Pós-Graduação em Neuropsicopedagogia Clínica e Institucional. O propósito da professora que ministrou a disciplina era refletir sobre as dificuldades enfrentadas pelos alunos na aprendizagem, principalmente em idade escolar, e os fatores relacionados ao uso demasiado de medicamentos, o que deveria ser feito junto aos pós-graduandos.

Como sugestão de início da aula a professora solicitou que os alunos formassem um círculo somente com as cadeiras, onde eles poderiam ter o contato direto com os seus colegas e, assim, olhar para o outro, formando, dessa forma, um círculo de diálogo e compreensão. Nesse momento os alunos deveriam deixar as suas classes, pois as mesmas significavam um obstáculo, uma forma de limitação entre eles, os colegas e o próprio professor.

\section{DESMISTIFICANDO AS DIFICULDADES DE APRENDIZAGEM EM SALA DE AULA POR MEIO DO CÍRCULO DE DIÁLOGO E COMPREENSÃO}

O diálogo, parte essencial do processo de empoderamento individual e comunitário, serve para gerar a racionalidade da comunicação (HABERMAS, 1989). Este autor aprofunda sua teoria da ação comunicativa para que esta se desenvolva de maneira clara, possibilitando a reivindicação de validade, de modo que os participantes de um diálogo tenham o consenso para que boas respostas sejam alcançadas diante da problemática, gerando um entendimento mútuo que, segundo Pranis (2010) e Pelizzoli (2014), seria fundamentado nos pilares do diálogo: a escuta - e dentro desta a Presença, a Atenção e o Silêncio.

Nesse caso, a problemática a ser tratada era a deficiência na aprendizagem de alguns alunos e o uso demasiado de medicamentos. Nesses círculos, estar plenamente presente, participante, é essencial para que o diálogo aconteça. Disponibilizar atenção ao que o outro expressa como sua verdade pessoal, sua história sendo compartilhada e o silêncio enquanto o outro fala, é uma forma de conectar-se com o que é exposto pelo outro participante do círculo no momento em que este faz uso da palavra. 
O processo de círculo é pré-concebido para discutir como a conversa acontecerá antes de discutir os assuntos difíceis. Consequentemente, o círculo trabalha os valores e diretrizes antes de falar sobre as diferenças ou conflitos, muitas vezes dando ênfase à construção de relacionamentos (PRANIS, 2010).

Mediante a construção do círculo, foi possível que os alunos se conhecessem meIhor. Cada um deles deveria dizer o nome, naturalidade e atuação profissional. Nesse momento foi possível saber que a grande maioria eram professores e outros haviam recentemente finalizado a faculdade. A partir de suas experiências pudemos abordar livremente, sem pré-julgamentos, ou mesmo sem nenhum julgamento externo, o conteúdo da aula.

Os relatos das práticas em círculos datam das raízes dos povos nativos do mundo e, especificamente, os Círculos de Diálogo dos indígenas da América do Norte, servindo de fonte de sabedoria para as culturas ocidentais modernas (PRANIS, 2010).

Com intuito de investigar as relações humanas para uma prática significativa de tais valores estruturantes, Harold Gatensby, pesquisador dos processos em círculo do povo Tlingit da cidade de Carcross, em Yukon, Canadá, tem aplicado a tradicional Roda da Medicina, igualmente dividida em quatro partes e que aborda que o tempo gasto no esforço para que os participantes do círculo se conheçam, a fim de criar entendimento e conexão, deve ser correspondente ao mesmo tempo gasto na discussão do problema e na criação de planos de ação (p. 57-58).

Por meio do círculo foi permitido a cada um dos alunos fazer uma autoinvestigação no processo de percepção da Teoria da Ação Comunicativa, quando os mesmos viram a sua importância perante os colegas, inclusive sendo comentado por um dos alunos: "que essa metodologia era extremamente interessante, pois eles estavam acostumados a chegarem nas disciplinas anteriores (já haviam cursado três disciplinas) $e$ sentarem cada um em seu devido lugar, que nenhum dos professores tinha permitido $e$ dado espaço para que os mesmos se conhecessem".

Em relação à segunda pergunta sobre o que significava aprendizagem para eles, os mesmos puderam refletir a sala de aula com os seus alunos, e muitas foram às respostas; entre elas: Conhecimento, descoberta de novas experiências, troca de conhecimento e que a aprendizagem, na grande maioria das vezes, está associada e é facilitada quando existe amor, quando existe compreensão entre professor e aluno, quando existe troca, afetividade. Inclusive foi possível fazer, nesse momento, uma relação com aquele aluno que aprende facilmente determinada disciplina e que em outra disciplina o mesmo aluno não tem interesse nenhum, tornando-se, muitas vezes, hiperativo, impaciente, ansioso.

A partir desses questionamentos, um dos primeiros objetivos da disciplina foi alcançado; era exatamente fazer com que o pós-graduando refletisse a sua realidade em sala de aula e permitisse, dessa forma, que ele reconhecesse o seu aluno como um ser ativo, que deve ter amor ao que aprende e que, muitas vezes, o que visualizamos como um distúrbio de aprendizagem nada mais é do que a falta de estímulo do professor em aplicar e trabalhar de uma forma diferenciada a disciplina, buscando novas metodologias e, de maneira diferenciada, fazer com que o aluno seja ativo na construção da sua própria aprendizagem. 
Nesse momento foi possível realizar uma relação com a forma como as outras disciplinas haviam sido ministradas no curso de Pós-Graduação e como eles estavam começando a disciplina de Psicofarmacologia e Aprendizagem. Eles estavam sendo sujeitos da construção da sua aprendizagem, não estavam sendo meros telespectadores. Os círculos de diálogo servem para: refletir sobre a importância e efeito da educação na vida dos profissionais envolvidos nessa área; dialogar como fomentar a participação do aluno em sala de aula, bem como a participação dos pais na educação dos seus filhos; valorizar a escola, a família e o(a) aluno(a); praticar a cidadania; e disseminar o conhecimento.

É necessário, no entanto, que o educador tenha conhecimento da dificuldade do aluno e de suas causas, para que respeite o seu desenvolvimento e busque novas metodologias ou adapte o material pedagógico a fim de que a sua aprendizagem não seja comprometida.

Alguns fatores devem ser considerados como desencadeadores da dificuldade de aprendizagem, como, segundo Gonçalves e Ovídio (2017, p. 4): “[...] mudança de escola, separação, desorganização na rotina familiar, problemas socioculturais e emocionais, envolvimento com drogas, efeito colateral de medicação, assim como tantos outros". É preciso identificar claramente os pontos que diferenciam problemas de aprendizagem ou distúrbio, como falta de interesse, esforço e atenção (VILLAR, 2013).

Após discutirmos sobre a aprendizagem, e com cada aluno trazendo as suas experiências e vivências, foi possível apresentar a parte mais teórica do conteúdo, a qual foi demonstrada pela professora responsável pela disciplina, sendo a mesma doutora em Ciências Biológicas - Bioquímica - e tendo um conhecimento mais específico do conteúdo sobre Farmacologia. A maioria dos pós-graduandos eram pedagogos e, consequentemente, tinham um conhecimento maior na área do ensino e educação.

Nesse segundo momento foram utilizados alguns slides para a discussão de assuntos relacionados à neurociência e à neuropsicopedagogia, incluindo a estrutura do neurônio, os neurohormônios, tanto os neuroativadores quanto os neurobloqueadores hormonais do nosso sistema, e a própria aprendizagem.

Entender a conexão cérebro $x$ aprendizagem, proposta a partir do conhecimento da Neurociência, apresenta-se como um dos assuntos mais procurados e um dos grandes desafios educativos. A interface entre cérebro $x$ aprendizagem necessita de muito investimento científico, mas são profissionais das mais diversas áreas que têm voltado seus estudos para este enfoque. Um dos maiores desafios enfrentados pelos educadores está em promover a aprendizagem de conhecimentos em alunos com dificuldades. O educando, com pouca ou nenhuma motivação para aprender, mais cedo ou mais tarde, acaba fracassando nas escolas, adquirindo a marca de apresentar dificuldades de aprendizagem. Sendo assim, alguns professores, com pouca ou nenhuma expectativa com relação a esses alunos, sentem-se pouco motivados para desenvolverem um ensino adequado, reforçando a possibilidade de fracasso (MACHADO, 2014). 
Nos processos neurofuncionais, as diferentes situações de aprendizagem modificam a estrutura física cerebral, estabelecendo ou eliminando conexões entre as células, causando mudanças na quantidade de substâncias químicas (neurotransmissores) (GARCIA, 1998).

Dessa maneira, nesses processos é importante que cada estrutura que exerça função exclusiva no processo de construção da aprendizagem esteja íntegra, pois, caso algum fator altere o curso desse, acarretará em um desvio.

Uma das áreas que vêm abrindo espaço dentro do âmbito de conhecimento é a Neuropsicopedagogia, que Hennemann (2012, p. 11) descreve

[...] como um novo campo de conhecimento que através dos conhecimentos neurocientíficos, agregados aos conhecimentos da pedagogia e psicologia vem contribuir para os processos de ensino-aprendizagem de indivíduos que apresentem dificuldades de aprendizagem (p. 11).

Essa área tem como princípio: 1ㅇ - a Educação; 2ㅇ - a Psicologia; e 3으 a Neuropsicologia. Educação no intuito de promover a instrução, o treinamento e a educação dos cidadãos; a Psicologia com os aspectos psicológicos do indivíduo; e, finalmente, a Neuropsicologia, com a teoria do cérebro trino, posto que aqui se oportuniza a teoria das múltiplas inteligências, proposta por Gardner (FERNANDEZ, 2010). Em nosso país a Sociedade Brasileira de Neuropsicopedagogia (SBNPP) foi fundada somente em 2014 e, de uma forma mais pontual, conceitua essa área como sendo:

[...] uma ciência transdisciplinar, fundamentada nos conhecimentos da Neurociências aplicada à educação, com interfaces da Pedagogia e Psicologia Cognitiva que tem como objeto formal de estudo a relação entre o funcionamento do sistema nervoso e a aprendizagem humana numa perspectiva de reintegração pessoal, social e educacional (SBNPP, 2014).

Em relação à Farmacologia foi demonstrado as diferentes classes de psicofármacos: ansiolíticos e hipnóticos, antidepressivos, antipsicóticos ou neurolépticos e estabilizadores do humor; suas indicações e contraindicações; efeitos colaterais e mecanismos de ação. O uso de psicofármacos configura-se como verdadeira epidemia mundial em virtude de seus efeitos hipnóticos, ansiolíticos, miorrelaxantes e anticonvulsivantes. São medicamentos que atuam no sistema nervoso central e que apresentam grande eficácia terapêutica, baixos riscos de intoxicação e dependência.

Em razão de os psicofármacos serem considerados drogas relativamente seguras, aliadas ao aumento vertiginoso de queixas de origem psíquica por parte dos usuários da atenção básica em saúde, foi gerado aumento no seu uso e nas prescrições médicas. O emprego abusivo, porém, tem gerado uma conduta de restrições à utilização dos psicofármacos baseada, sobretudo, na dependência que causa grande incidência dos eventos adversos, como diminuição da atividade psicomotora, prejuízos na memória, desinibição paradoxal, tolerância, dependência e potencialização do efeito depressor pela interação com outras drogas depressoras, principalmente o álcool, depressão e distimia (CAVALCANTE et al., 2015). 
Conforme a aula ia sendo ministrada e o conteúdo apresentado, novos debates surgiram, incluindo experiências pessoais sobre o uso de alguns medicamentos e até mesmo alguns psicofármacos que estão sendo utilizados em abundância, principalmente por crianças que são, muitas vezes, consideradas com déficit de atenção e aprendizado. Esses transtornos são cientificamente estudados; são processos que têm critérios para diagnóstico. A banalização da medicalização ocorre porque qualquer pessoal julga que a criança mais desatenta e hiperativa tenha algum distúrbio. Todos temos um ou outro sintoma, mas o diagnóstico é feito segundo um conjunto de sintomas, que, quando tratados, trazem benefícios significativos à vida da pessoa e da família.

No decorrer da aula dúvidas surgiram, entre elas: Existe algum psicofármaco que seu uso seja seguro pelo paciente? O aluno, ao entrar em férias, pode parar de imediato o uso desse medicamento? Existem efeitos colaterais caso o seu uso seja inibido imediatamente? Em vários momentos o pós-graduando voltava ao seu ambiente escolar trazendo inúmeras experiências já vividas, situações encontradas no seu dia a dia e relatos sobre alunos que faziam uso de piscofármacos e que, muitas vezes, se acreditava não ser necessário o seu uso, pois o aluno, com um pouco de atenção e segurança que, muitas vezes, era passado pelo próprio professor, mudava visivelmente o seu quadro, o que podia ser notado no momento da troca de disciplinas e, principalmente, de professor.

Durante toda a aula pode-se verificar fortemente a presença da Pedagogia Social em seu discurso, lidando com as questões sociais do nosso dia a dia no convívio e no trabalho com outras pessoas, tanto com os profissionais quanto com os próprios alunos, sabendo lidar com as questões e com as perguntas do ambiente escolar de um grupo de indivíduos, ajudando o outro a dar o próximo passo em seu desenvolvimento pessoal. Significa "agir sobre si mesmo, com outros e com as perguntas da sociedade, de tal forma que nossa ação torne possível o desenvolvimento sadio de outras pessoas e das condições sociais (BRASIL, 2016).

Sugere-se, a partir disso, que todo o processo de aprendizagem se torne mais abrangente, utilizando-se dos conhecimentos da psicologia como uma ferramenta durante os processos de aprendizagem, identificando no aluno as emoções e os sentimentos conflitantes, situações familiares que possam estar atrapalhando o processo de aprendizagem e questões de autoestima ou sociais que precisem ser trabalhadas na escola, verificando as problemáticas do processo de aprendizagem com a finalidade de escolher as melhores estratégias e ferramentas para favorecer o aprendizado (MARQUES; PICETTI, 2016).

Em nossa sociedade a aprendizagem tem um valor cultural, uma vez que o bom desempenho escolar é indicativo de futuro sucesso social e sempre houve uma preocupação com as crianças que tinham dificuldades para aprender. Com a gratuidade no Ensino Fundamental, todavia, o acesso à escola deixou de ser restrito e, consequentemente, aumentaram-se as queixas sobre alunos que têm dificuldades de aprendizagem. Neste contexto surgiu o mau desempenho escolar que se apresenta como um rendimento escolar, habilidades cognitivas e escolaridade abaixo do esperado para determinada idade (SIQUEIRA; GURGEL-GIANNETTI, 2011). 
De acordo com Santos e Pereira (2012), dificuldades de aprendizagem são comumente expostas no ambiente escolar, o que vem preocupando pesquisadores sobre como e de que forma são feitos os diagnósticos nas crianças. Os professores, ao depararem-se com crianças que não satisfazem os planejamentos e seus instrumentos de controle, acabam rotulando, e até, às vezes, menosprezando, essa criança sob o argumento de ela ser problemática ou hiperativa. Ao passar os seus conflitos para os gestores, acabam recebendo orientações divergentes com a situação. Esse jogo de falta de conhecimento provoca nos professores e gestores um ambiente de incompetência e alienação. Fica, então, a cargo de psicólogos e psicopedagogos tomar as devidas incumbências de solucionar as dificuldades de aprendizagem (p. 3).

\section{A UTILIZAÇÃO DE VÍDEOS COMO FERRAMENTAS PARA A CONSCIENTIZAÇÃO DE PROFESSORES DIANTE DE SEUS ALUNOS EM SALA DE AULA E O USO DE PSICOFÁRMACOS}

Aprendizagens são chaves para mudanças, mas para toda chave se faz necessário uma fechadura, que pode ser o simbolismo de sentimentos e emoções. Segundo Damásio (2013), não há como separar "razão da emoção". A aprendizagem passa pela esfera da emoção; não há como aprender sem sentir o gostinho do tempero da emoção, pois, conforme Oliveira (2013), "em um nível básico, as emoções são parte da regulação homeostática e constituem-se como um poderoso mecanismo de aprendizagem". O processo de aprender envolve a decodificação do mesmo e o entendimento de que estamos diante de um mapa moldável, onde cada indivíduo vai se moldando conforme as modificações dos ambientes.

No ano de 1996, com a criação da Lei de Diretrizes e Bases da Educação Nacional (LDBEN/9.394-96) e de suas propostas pedagógicas relacionadas à educação infantil, é mencionado que a criança e o adolescente devem ser o centro do planejamento curricular, pois esses são considerados sujeitos históricos e de direitos que, nas interações, nas relações e práticas cotidianas, constroem sua identidade pessoal e coletiva, brincam, imaginam, fantasiam, desejam, aprendem, observam, experimentam, questionam e constroem sentidos sobre a natureza e a sociedade, produzindo Cultura (BRASIL, 2009).

Dessa forma, o professor deve buscar novas maneiras de se aproximar dos seus alunos por meio de metodologias ativas, trazendo o aluno como formulador do seu próprio conhecimento, estando o docente apenas como um facilitador e norteador na busca da aprendizagem. Existem discussões que relatam a forma negativa com que o aluno recebe essa nova configuração de aprendizagem, em razão de a figura do professor não estar como detentor do saber e, sim, como um mediador em direcionar o modo de buscar o conhecimento. É necessário perpassar por mudanças que tragam resultados positivos ao longo do tempo.

Para o ensino da psicofarmacologia, a utilização de filmes tem contribuído para a reflexão e o entendimento de situações clínicas (FARRÉ, et al., 2004; SANTOS; NORO, 2013), principalmente na elaboração de planos curriculares que queiram contemplar crianças e adolescentes com transtornos de aprendizagem, dando suporte ao proces- 
so de ensino-aprendizagem. É um lugar de pensar, descobrir, reinventar, criar e recriar, enfim, vivenciar ideias, sentimentos e experiências, num movimento de reconstrução individual e coletiva (ANASTASIOU; ALVES, 2004).

Nesse contexto foi sugerido aos pós-graduandos que assistissem a três filmes. Um deles um clipe denominado Estudo Errado, do álbum Ainda é só o começo, escrito pelo compositor Gabriel Pensador (1995), o qual se encontra disponível no Youtube. Essa música tem a finalidade de ressaltar a situação educacional do nosso país, levando-nos à reflexão acerca do método tradicional de ensino, no qual o aluno aceita as informações repassadas acomodando-se diante de tal situação e obedecendo às normas estabelecidas pela escola, ou seja, o aluno tem o papel de memorizar os conteúdos transmitidos, sem possibilidade de questioná-los, configurando-se a educação bancária.

Outro vídeo mencionado foi "Quando a escola é de vidro" de Ruth Rocha [1986?], o qual também se encontra disponível no Youtube e vem ao encontro do "Estudo Errado", e mostra, mais uma vez, a realidade do que encontramos em muitas escolas ainda nos dias de hoje, onde a criança é rotulada dentro de suas especificidades, comparando a escola como um recipiente de vidro, que o aluno pode ver, mas não pode tocar nem ouvir, ficando preso ao educador e seu conteúdo programado. Nossas escolas são como gavetas, em que não ocorre interação entre disciplinas, não existe interdisciplinaridade entre elas e não há diálogo entre os professores na grande maioria das vezes. Se essas gavetas, esses recipientes de vidros fossem abertos e permitissem que o aluno pudesse expressar a sua realidade, a cultura que trouxe do seu próprio lar unindo aos ensinamentos que terá em sala de aula, a aprendizagem tomaria outros rumos; seria algo mais interessante, algo que despertaria a criatividade do aluno, envolvendo o seu próprio crescimento escolar; enfim, ela tomaria outros rumos. A criança aprende a conviver com as diferenças, tem liberdade para falar do seu conhecimento de mundo, dando mais sentido ao seu aprendizado. Tem contato com o mundo, aprende que as pessoas não usam rótulos, mas defendem bandeiras pelo que acreditam.

Nesse mesmo vídeo, Ruth Rocha [1986?] ainda enfatiza:

A liberdade muitas vezes assusta e, mesmo que não seja aceita com tranquilidade, a liberdade abre outros caminhos... Faz com que o ensino aprendido possa ser usado no contato do educando com o mundo, para que ele se sinta importante e que nele desperte o desejo de aprender mais. Juntar o que se sabe com o que se aprende é andar de braços dados com a escola, pois juntamos o que ela pode proporcionar com o que se quer para a vida. Às vezes, porém, é preciso destruir para construir e começar tudo de novo e isso nem sempre significa perdas, mas acréscimo de saber.

O conhecimento pode ser construído fora da sala de aula, fora do seu próprio mundo. A interação constrói conceitos. "Criar pessoas melhores que saberão respeitar as diferenças. É como uma dança, em que cada um contribui com o que sabe. Tal dança é a ciranda do saber, que aceita cada um com o seu ritmo, sua dificuldade, sua necessidade".

O terceiro filme utilizado foi "João, preste atenção!" de Patricia Secco. Esse filme retrata os sentimentos de um menino que descobre que tem dislexia e, consequentemente, apresenta dificuldades de aprendizagem. Assim como João, inúmeras crianças 
são incapazes de utilizar adequadamente alguns instrumentos básicos de comunicação, como a leitura, a escrita e a interpretação de textos ou, até mesmo, a aprendizagem de uma segunda língua, sendo, muitas vezes, desmotivadas pelo baixo desempenho na vida escolar. No decorrer do ano letivo e com a ajuda de uma psicóloga, ele consegue fazer com que todos compreendam melhor as dificuldades de João. $\mathrm{O}$ distúrbio que João apresenta, a dislexia, não impede que ele tenha uma vida escolar normal, apenas requer atenção especial, amizade e o apoio dos pais e professores.

Para tal feito se fazem necessários trabalhos investigativos que identifiquem no aluno as emoções e os sentimentos conflitantes, situações familiares que possam estar atrapalhando o processo de aprendizagem e questões sociais que precisem ser trabaIhadas na escola, verificando as problemáticas do processo de aprendizagem com a finalidade de escolher as melhores estratégias e ferramentas para favorecer o aprendizado (MARQUES; PICETTI, 2016).

Após visualizados os três vídeos, os alunos, em círculo, continuaram a discussão sobre as situações encontradas em suas turmas e ainda mencionaram inúmeros casos em que os pais, muitas vezes, obrigavam seus filhos a tomar medicamentos. É necessário conhecer o aluno, seu histórico de vida, considerando que boas doses de amor, carinho e atenção são fundamentais durante o seu desenvolvimento escolar.

Inclusive uma das alunas relatou uma situação que havia ocorrido em sua turma com um de seus alunos:

um aluno adolescente, afastado de todos os demais, que nunca queria participar de evento nenhum na escola, um aluno quieto, aparentemente insatisfeito e que os pais relatavam que não levavam ele aos eventos, pois ele não demonstrava interesse nenhum e que sempre pedia para não ir". Com o passar do tempo, a professora (aluna da turma de pós) começou a dar uma atenção especial ao aluno, dando mais carinho, solicitando que ele em muitas vezes a ajudasse em atividades rotineiras da sala de aula. Como resultado final, esse aluno começou a ser mais participativo, começou a demonstrar interesse em participar dos eventos, e a maior e melhor resposta positiva que esse aluno pode dar a essa professora foi no final do ano, quando, na festa de encerramento da escola, o menino solicitou aos seus pais que ele gostaria de estar presente, inclusive conversando e sendo completamente ativo com os seus colegas.

Planejar uma proposta de intervenção ajuda bastante para que seja feito um trabalho mais bem desenvolvido. Algumas estratégias para aliviar as dificuldades geradas é tentar organizar um atendimento individual. Para elaborar uma proposta de intervenção é necessário que o professor se adeque a todas as possibilidades que a escola disponibiliza para que o aluno possa desenvolver atividades específicas. O professor deve buscar um completo equilíbrio entre a escola e a família. É preciso ter clareza para facilitar o entendimento dos demais envolvidos (MACHADO, 2014).

Sabe-se que a proposta do sistema educacional brasileiro é dar para cada aluno a oportunidade de aprender de acordo com sua capacidade. Januzzi (2004) considerou 
Que a prática educativa voltada para a pessoa com dificuldades especiais no Brasil é influenciada pelo modo de pensar e de agir em relação ao diferente. Depende da organização social mais ampla, levando em conta a base material e ideológica do processo educativo.

Assim, há muitos fatores que podem influenciar positiva ou negativamente no aprendizado de cada aluno. Quando, todavia, se trata de transtornos, deve haver um apoio e um acompanhamento mais próximos.

\section{CONSIDERAÇÕES FINAIS}

Por meio do círculo de diálogo e compreensão, o qual é bastante utilizado para sanar algumas situações do nosso dia a dia e serviu como uma estratégia para discutirmos mais abertamente as deficiências na aprendizagem e o uso demasiado de medicamentos, principalmente em indivíduos em idade escolar, foi possível verificar que, muitas vezes, o problema é amenizado com carinho, amor, dedicação e afetividade pela parte dos professores e familiares, posto ser considerado uma questão pluricausal.

A disciplina de Psicofarmacologia e Aprendizagem foi construída entre o professor e os pós-graduandos, o que permitiu que não fosse algo engessado, pronto e, sim, algo preparado durante as oito horas em que a mesma foi ministrada. Assim, o conhecimento tornou-se bem mais rico; cada um dos alunos participantes pode explorar as suas experiências profissionais vivenciadas em sala de aula, permitindo que as mesmas fossem discutidas em um grande grupo. A metodologia utilizada no círculo de diálogo e compreensão permite que os participantes do círculo tenham a sua vez de fala e os demais possam escutar atentamente o que é exposto. Essa metodologia pode ser acompanhada, em alguns momentos, por relatos de experiências trazidos pelo próprio professor, além da utilização de dois filmes que serviram como embasamento para que o discurso se tornasse mais profundo.

Finalizamos, após a construção dos círculos de diálogo e compreensão, e de discussões tanto teóricas quanto de experiências práticas, relatando que, muitas vezes, o uso de medicamentos em indivíduos, principalmente na infância e adolescência, ocorre de forma errada, com grandes quantidades, altas dosagens e, às vezes, sem um diagnóstico correto. É fundamental que sejam realizados diagnósticos eficazes, e isso envolve vários profissionais e áreas, entre elas Farmacologia, Neurociência, Pedagogia Social e Psicologia. É necessário conhecer o aluno, seu histórico de vida, considerando que boas doses de amor, carinho e atenção são primordiais durante o seu desenvolvimento escolar.

\section{REFERÊNCIAS}

ANASTASIOU, Lea das Graças Camargo; ALVES, Leonir Pessate. Estratégias de ensinagem. In: ANASTASIOU, Lea das Graças Camargo, ALVES, Leonir Pessate. Processos de ensinagem na universidade: pressupostos para as estratégias de trabalho em aula. 3. ed. Joinville: Univille, 2004. p. 67-100

BRASIL. Lei de Diretrizes e Bases da Educação Nacional. Lei n. 9.394/96, de 20 de dezembro de 1996.

BRASIL. Conselho Nacional de Educação; Câmara de Educação Básica. Resolução CNE/CEB no 5, de 17 de dezembro de 2009. Fixa as Diretrizes Curriculares Nacionais para a Educação Infantil. Diário Oficial da União, Brasília, DF: MEC, 18 dez. 2009, Seção 1, p. 18. 
BRASIL. Sociedade Antroposófica no Brasil. Pedagogia social. Desenvolvido por Contraste Studio. 2016. Disponível em: http://www.sab.org.br/portal/desenvolvimento-social/72-pedagogia-social Acesso em: 5 jan. 2019.

CAVALCANTE, Heitor Augusto Otaviano et al. Consequências do uso abusivo de psicofármacos benzodiazepínicos. Revista Conexão Eletrônica, Três Lagoas, v. 12, n. 1, 2015.

FARRÉ, Magi et al. Putting clinical pharmacology in context: the use of popular movies. J Clin. Pharmacol., [Internet], 44(1), p. 30-36, 2004 DOI: https://doi.org/10.1177/0091270003260679.

FERNANDEZ, Ana C. G. Aportes de la Neuropsicopedagogía a la pedagogia. La visión de Jennifer Delgado en: Desmistificación de la Neuropsicopedagogía. Colômbia, ASOCOPSIP, 2010. Disponível em: http:// licenciadospsicologiaypedagogia.blogspot.com/2010/02/aportes-de-la-neuropsicopedagogia-la.html Acesso em: 15 maio 2019.

GARCIA, J. N. Manual de dificuldades de aprendizagem. Porto Alegre: Artmed, 1998.

GONÇALVES, A. J.; OVÍDIO, J. Dificuldade de aprendizagem. Revista Maiêutica, Indaial, v. 5, n. 1, p. 43-48, 2017.

HABERMAS, Jürgen. Consciência moral e agir comunicativo. Trad. Guido de Almeida. Rio de Janeiro: Tempo Brasileiro, 1989.

HENNEMANN, Ana L. Neuropsicopedagogia clínica: relatório de estágio. Novo Hamburgo: Censupeg, 2012.

JANUZZI, A. A educação do deficiente no Brasil: dos primórdios ao início do séc. XXI. Campinas, São Paulo: Autores Associados, 2004.

MACHADO, Tiago Ribeiro. Os desafios do professor alfabetizador. Seduc. 2014. Disponível em: http:// www.seduc.mt.gov.br/Paginas/OS-DESAFIOS-DO-PROFESSOR-ALFABETIZADOR.aspx. Acesso em: 24 nov. 2018.

MARQUES, Tania Beatriz Iwaszko; PICETTI, Jaqueline Santos. O que é psicopedagogia: uma breve revisão bibliográfica. Psicopedagogia e TICs. Porto Alegre: Editora da UFRGS, 2016. Disponível em: http://www. lume.ufrgs.br/handle/10183/151202. Acesso em: 18 out. 2018.

OLIVEIRA, Nythamar. Damásio, neurociência e neurofilosofia. Porto Alegre: Fronteiras do Pensamento, 2013. Disponível online em: http://www.fronteiras.com/artigos/damasio-neurociencia-e-neurofilosofia. Acesso em: 12 maio 2016.

PELIZZOLI, Marcelo L. Círculos de diálogo: base restaurativa para a Justiça e os Direitos Humanos. In: Direitos Humanos e Políticas Públicas, Curitiba: Ed. Universidade Positivo, p. 131-151, 2014. Disponível em: http://www.senge-pr.org.br/wpcontent/uploads/2015/03/DIREITOS-HUMANOS-E-POL\%C3\%8DTICASP\%C3\%9ABLICAS.pdf. Acesso em: 19 jan. 2019.

PENSADOR, Gabriel. Estudo errado. Álbum Ainda é só o começo. 1995. Disponível em: https://www.youtube.com/watch?v=SQVbrILJxac

PRANIS, Kay. Processos circulares. Tradução Tônia Van Acker. São Paulo: Palas Athena, 2010.

ROCHA, Ruth. Quando a escola é de vidro. In: ROCHA, Ruth. Este admirável mundo louco. Rio de Janeiro: Editora Salamandra. [1986?]. Disponível em: https://www.youtube.com/watch?v=G_XBgV91oqc

SANTOS, Larissa Batista Carvalho; PEREIRA, Mônica Pereira Reis Amarante Dória. Dificuldade de aprendizagem: concepções e problemáticas contemporâneas. 2012. Disponível em: httpeduconse.com.br2012eixo_15PDF16.pdf. Acesso em: 22 nov. 2018.

SANTOS, Setsuko Noro dos; NORO, André. O uso de filmes como recurso pedagógico no ensino da neurofarmacologia. Interface, Botucatu, [Internet], 17(46), p. 705-14, 2013. Disponível em: http://dx.doi. org/10.1590/S1414-32832013005000021. Acesso em: 7 nov. 2018.

SECCO, Patricia. João, preste atenção! Campinas, SP: Educard Paschoal, 1995. Disponível em: https:// www.youtube.com/watch?v=3PeK_w--IDM

SIQUEIRA, Cláudia Machado, GURGEL-GIANNETTI, Juliana. Mau desempenho escolar: uma visão atual. Rev. Assoc. Med. Bras., v. 57, n. 1, p. 78-87, 2011.

SBNPP. O que é Neuropsicopedagogia. Joinville: Sociedade Brasileira de Neuropsicopedagogia, 2014.

VILLAR, J. M. G. Discalculia na sala de aula de matemática: diagnóstico e intervenção. 2013. 12 f. Tese (Doutorado em Matemática) - Universidade Federal de Juiz de Fora, Juiz de Fora, 2013.

WEISS, A. M. L.; CRUZ, M. L. R. da. Compreendendo os alunos com dificuldades e distúrbios de aprendizagem. In: GLAT, R. (org.). Educação inclusiva: cultura e cotidiano escolar. 2. ed. Rio de Janeiro: 7Letras, 2011.

WEISS, M. L. L. Combatendo o fracasso escolar. Obstáculos à aprendizagem e ao desenvolvimento da leitura. In: WEISS, M. L. L.; WEISS, A. Vencendo as dificuldades de aprendizagem escolar. Rio de Janeiro: Wak, 2009. 